\title{
Interprofessional Practice in the Emergency Service: specific and shared assignments of nurses
}

\author{
Prática interprofissional no Serviço de Emergência: atribuições especificas e compartilhadas dos enfermeiros \\ La práctica interprofesional en el Servicio de Emergencia: asignaciones específicas y compartidas de los enfermeros
}

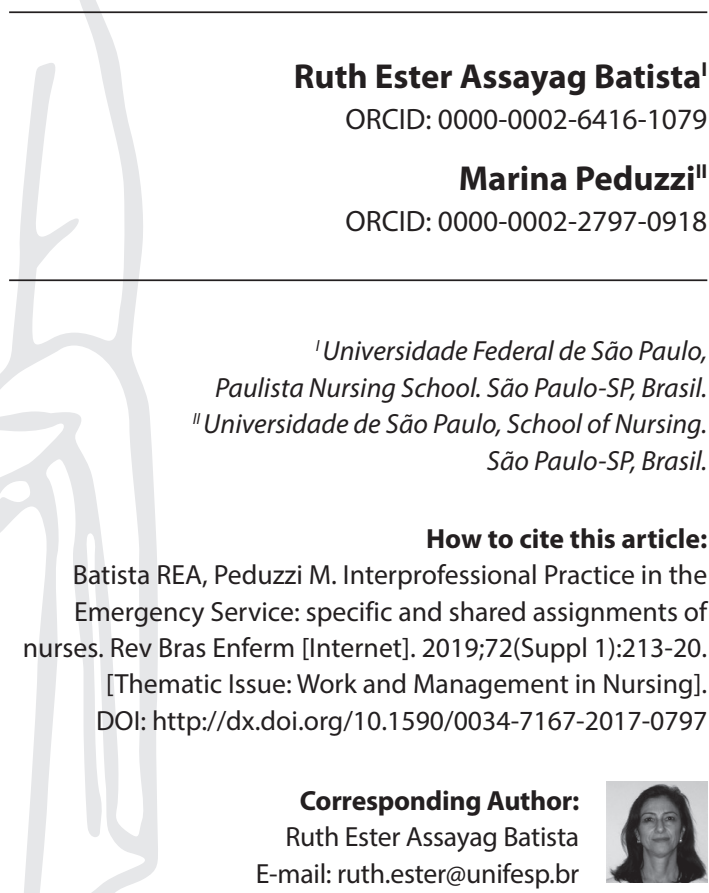

Submission: 12-12-2017

Approval: 05-23-2018

\begin{abstract}
Objective: To map and categorize, according to the Nursing Interventions Classification (NIC), the specific assignments of the nurses and to identify the assignments shared with doctors and physiotherapists in the Emergency Service. Method: Descriptive exploratory study, carried out in two phases: first, the analysis of dissertations /theses from the database of the Center for Studies and Research of the Brazilian Nursing Association; Second, the use of the Delphi Technique to reach the consensus about which assignments were specific to the nurse and which were shared with physiotherapists and doctors. Results: The results were $45.7 \%$ for specific to the nurses, $14.2 \%$ for shared with physiotherapists and/or doctors, and in $40 \%(n=42)$ there was no consensus about the sharing of assignments. Conclusion: The sharing of actions among professionals shows an increase in the scope of the practice of professions and the constitution of a common sphere of work, but the high number of assignments with no consensus among specialists can be a potential factor in conflicts due to the lack of definition of these assignments. Descriptors: Interprofessional Relations; Patient Care Team; Cooperative Behavior; Nursing; Emergency Service.
\end{abstract}

\section{RESUMO}

Objetivo: Mapear e categorizar, de acordo com a Classificação das Intervenções de Enfermagem, as atribuições específicas dos enfermeiros e identificar as compartilhadas com médicos e fisioterapeutas nos Serviço de Emergência. Método: Estudo exploratório descritivo, realizado em duas fases: a primeira, constituída por análise de dissertações/ teses da base de dados do Centro de Estudos e Pesquisas da Associação Brasileira de Enfermagem. Na segunda, utilizou-se a Técnica Delphi para obtenção de consenso sobre quais atribuições eram especificas do enfermeiro e quais eram compartilhadas com fisioterapeutas e médicos. Resultados: $45,7 \%$ específicas dos enfermeiros, $14,2 \%$ compartilhadas com fisioterapeutas e/ou médicos e em $40 \%$ ( $n=42)$ não houve consenso sobre o compartilhamento das atribuições. Conclusão: O compartilhamento de ações entre os profissionais mostra ampliação do escopo de prática das profissões e constituição de esfera comum de trabalho, mas o elevado número de atribuições sem consenso entre os especialistas pode ser área de potenciais conflitos pela indefinição das atribuições. Descritores: Relações Interprofissionais; Equipe de Assistência ao Paciente; Comportamento Cooperativo; Enfermagem; Serviço de Emergência.

\section{RESUMEN}

Objetivo: Mapear y categorizar de acuerdo con la Clasificación de las Intervenciones de Enfermería las atribuciones específicas de los enfermeros e identificar las compartidas con médicos y fisioterapeutas en el Servicio de Emergencia. Método: Estudio exploratorio descriptivo, realizado en dos fases: la primera constituida por análisis de disertaciones/ tesis de la base de datos del Centro de Estudios e Investigaciones de la Asociación Brasileña de Enfermería (Centro de Estudos e Pesquisas da Associação Brasileira de Enfermagem). En la segunda, fue utilizada la Técnica Delphi para obtener consenso sobre cuáles atribuciones eran específicas de los enfermeros y cuáles eran compartidas con fisioterapeutas y médicos. Resultados: $45,7 \%$ específicas de los enfermeros; $14,2 \%$ compartidas con fisioterapeutas y/o médicos; y en $40 \%(n=42)$ no hubo consenso sobre el reparto de las atribuciones. Conclusión: El intercambio de acciones entre los profesionales muestra la ampliación del alcance de la práctica de las profesiones y la constitución de una esfera común de trabajo, pero el elevado número de atribuciones sin consenso entre los especialistas puede ser un área de potenciales conflictos por la indefinición de las atribuciones.

Descriptores: Relaciones Interprofesionales; Equipo de Asistencia al Paciente; Comportamiento Cooperativo; Enfermería; Servicio de Emergencia. 


\section{INTRODUCTION}

In the Emergency Services (ES), specialized teams provide assistance to patients of high complexity in a dynamic environment, characteristics that make these units to be of a high risk for errors, in which communication, cooperation and coordination are essential for the effective care ${ }^{(1)}$. Associated with this dynamic environment there is overcrowding of these services, which is a worldwide phenomenon and has among its causes, the fact of becoming the gateway for access to more technological and resolutive assistance due to: the lack of structure and organization of the health systems; the stay of patients in the unit for long periods because of the lack of rear-recovery beds and the waiting time for care ${ }^{(1)}$. With this overview, the healthcare quality can be compromised because there is association between overcrowding and increased mortality in the units ${ }^{(2)}$.

The increase in demand for care in these units requires interaction and optimization of the competencies of the professionals involved in this care to reach the quadruple aim, proposed by Bodenheimer, for health services in the care delivery. These aims are to improve the patient experience and the population health, to reduce costs and improve the experience of health professionals in providing care $^{(3)}$. Studies show that interprofessional practice (IPP) is capable of increasing the satisfaction of professionals and patients regarding the care ${ }^{(4)}$, in addition to reducing treatment $\operatorname{costs}^{(5)}$. A review study identified seven studies with positive results of IPP introduction in the ES, such as improvement in the safety culture of the patient and collaborative behavior and reduction of the clinical errors rate of the interprofessional team ${ }^{(6)}$.

The IPP has been world widely recommended as an alternative to the reorganization of specialized work as it has a more comprehensive approach towards comprehensive health care and can contribute to improve the quality and effectiveness of health care $^{(7)}$. The IPP is a complex process in which there is an combination of professionals with different backgrounds, who share expertise, knowledge and skills with the purpose of providing care that has an impact on the health of the individuals ${ }^{(8)}$. The IPP can also contribute to the harmonization of practice scopes of the different professions that provide care for patients, since each of them promotes a diverse training and performance, with different conceptions about patients and the care needs they present ${ }^{(9)}$.

In order to be effective and to result in the benefits reported in the literature ${ }^{(10)}$, the implementation of IPP imply some conditions, including personal characteristics such as patience and tolerance, respect and understanding of the rules, trust and friendly relationships among peers, correct delegation of activities, and willingness to share new skills. Other elements identified as essentials are the characteristics of the team, such as proper diversity of team members' abilities, attitude of mutual respect, flexibility of individuals and staff, effective communication and, last but not least, clarity of role with regarding the respective areas of activity of each profession ${ }^{(10-13)}$. Studies have shown that there may be conflicts in the development of the IPP(14-15), and it have already been identified in the literature barriers to its introduction, such as lack of knowledge, inability to contribute with other professionals and weak competition between the areas of practice ${ }^{(16)}$ Publications point out that the clarity of the assignments of the team members is a fundamental assignment of IPP(10-13) so that, in this study, it is proposed to identify and to analyze the assignments of the nurses in the ES teams.

The study is linked to a broader research, which analyzes the action of nurses, physiotherapists and doctors of the Emergency Units, driven by the need for better understanding of interprofessional work in the ES in the Unified Health System (SUS) scenario in Brazil, with a view to further integration within the scope of the Healthcare Network (RAS).

\section{OBJECTIVE}

To map and categorize according to the Nursing Interventions Classification (NIC), the specific assignments of nurses in Emergency Services.

To identify which nurses' assignments are shared with doctors and physiotherapists in the teams that work in the Emergency Service, in order to favor collaborative interprofessional practice.

\section{METHOD}

\section{Ethical aspects}

It was followed the guidelines of the Resolution 466/2012 of the National Health Council, and it started after the approval of the Research Ethics Committee of the Universidade de São Paulo. All the participants were informed about the research and signed an informed consent form.

\section{Scenario and study period}

It is a descriptive exploratory study, carried out in two phases: first, the analysis of dissertations/theses from the database of the Center for Studies and Research of the Brazilian Nursing Association (CEPEn-ABEn) inserted in the Virtual Health Library (VHL) - Nursing ${ }^{(17)}$; Second, the use of the Delphi Technique to reach the consensus about which assignments were specific to the nurse (nursing team) and which were shared with physiotherapists and doctors that work in the ES.

\section{Study protocol}

In the first phase, the database of Theses and Dissertations of ABEn-CEPEn was consulted, which is intended to encourage the development and dissemination of nursing research, to organize and preserve historical documents of the profession; this is the largest bank of theses and dissertations in the field of Nursing in Brazil, with more than 4,000 works registered in its collection, comprising the period from 2001 to $2014^{(17)}$. Initially, dissertations and theses were selected, according to the inclusion criterion previously defined (include in the title the words emergency and/or urgency). After this first selection, the analytical reading was made to identify and list of all the assignments described in dissertations and theses. The tools to collect data was elaborated by the authors and consisted of the following information: title of the thesis/dissertation, authors, university in which the survey was conducted, year of publication, design and population of the 
study, and the assignments identified. This tool was not validated and the information was stored in a database in Excel ${ }^{\circ}$. Since the nurse is responsible for all the activities performed by the nursing team, were considered as activity of nurses both the private actions and the ones that are delegated to technicians and nursing assistants. It were excluded the documents that addressed the emergency situation outside Brazil, in the pre-hospital and the unavailability of theses and dissertations in digital format. Data were collected between July and November of 2016.

In the second stage of the study, the identified assignments comprised a tool for application through the Delphi ${ }^{(18)}$ technique, aiming to arrive at a consensus on the specific and shared activities of nurses in the ES. To standardize the language, allowing its comprehension in different scenarios, the list of activities was categorized according to the Nursing Interventions Classification (NIC) ${ }^{(19)}$. The Delphi technique is a method to structure the group communication, in order to allow a group of individuals (experts) to work on a certain phenomenon to achieve consensus, in this case, regarding the assignments of nurses in the ES. Regarding the number of experts, the literature suggests a minimum number of five as sufficient for control of concordance, and it is recommended between $50 \%$ and $80 \%{ }^{(18)}$.

\section{Analysis of results}

The experts were selected by the snowball sampling, a nonprobabilistic sample form, which uses reference chains. In this specific sampling it is not possible to determine the probability of selection of each participant in the survey ${ }^{(20)}$. The first expert, randomly selected in the database of Curiculum lattes, indicated another specialist having as criterion the minimum qualification of master and experience in education, research or assistance in Emergency Nursing.

In this study it was defined $80 \%$ consensus and the number of seven nurses experts. Three rounds were held to achieve consensus through the Delphi Technique and the questionnaire was sent to the experts via the Google forms requesting they indicate if the assignments were performed by the nurse in the ES; If yes, to answer if the assignment was specific or shared with doctors, physical therapists or both. In addition to these issues, there was an open question for the expert to add assignments not listed.

\section{RESULTS}

The panel of experts was composed of female professionals, with an average age of 31 years, and average time 14.4 years training, with master degree and experience in education, research or assistance in the emergency field. It was registered experience working in public hospital (57.1\%) and in public and private hospital (42.9\%).

The search at the CEPEn-ABEn thesis/dissertation databank resulted in 25 dissertations/theses, of which eight were excluded: three, because they were performed in pre-hospital care; one, because it was carried out abroad; and four because they were not found in the digital format. Among 17 remaining dissertations, four did not address the assignments of nurses in the ES, of which 13 were selected, and the reading of these dissertations/theses resulted in 101 assignments, among which 79 could be denominated according to the Nursing Interventions Classification (NIC) and 22 did not correspond to the NIC taxonomy, and were grouped as non-cataloged activities (NCA). In the first round of the Delphi Technique four assignments were included by the experts, totaling 105. Among these assignments, 48 were specific, 15 shared between physiotherapists and doctors, and 42 with no consensus (Table 1)

Of the 48 assignments identified as specific of nurses, 35 were categorized by the NIC and 13 were not categorized (Chart 1).

Table 1 - Assignments identified in the theses and dissertations database of the Brazilian Nursing Association - Nursing Research Center and the assignments included by the experts, ( $N=105)$ São Paulo, Brazil, 2017

\begin{tabular}{lcc}
\hline Sharing of activities & $\mathbf{n}$ & $\%$ \\
\hline With no consensus & 42 & 40.00 \\
Specific of nurses & 48 & 45.70 \\
Shared with physiotherapist & 1 & 0.97 \\
Shared with doctors & 12 & 11.40 \\
Shared with doctors and physiotherapist & 2 & 1.93 \\
Total & 105 & 100 \\
\hline
\end{tabular}

Chart 1 - Specific assignments of nurses in the Emergency Service, categorized according to the Nursing Interventions Classification (NIC) São Paulo, São Paulo, Brazil, 2017

\begin{tabular}{|l|}
\hline Assignments specific of nurses \\
\hline 1) 0466 - Enema administration: Instillation of a solution in the lower gastrointestinal tract. \\
\hline 2) 0590 - Control of Urinary Elimination: Management of an excellent standard of urinary elimination. \\
\hline 3) 0840 - Positioning: Deliberately drive a patient or body part to promote physiological and/or psychological well-being. \\
\hline 4) 1080 Gastrointestinal catheterization: Insertion of a tube into the gastrointestinal tract. \\
\hline 4) 1080 - Gastrointestinal catheterization care: Management of patient with gastrointestinal catheter. \\
\hline 6) 1056 - Enteral feeding tubes: Supply of nutrients and water through a gastrointestinal catheter. \\
\hline 7) 1050 - Feeding: Providing nutritional intake for patients who are unable to feed themselves. \\
\hline 8) 1610 - Bath: Clean the body for the purpose of relaxation, cleanliness and recovery. \\
\hline 9) 1630 - Dress: Choice, placing and removal of clothes of a person who can not do it alone. \\
\hline 10) 1720 - Promotion of Oral Health: Promotion of oral hygiene and dental care for the patient with normal oral and general health. \\
\hline
\end{tabular}


Chart 1 (concluded)

\section{Assignments specific of nurses}

11) 2300 - Medicines administration: Prepare, administer and evaluate the efficacy of prescription and over-the-counter medicines.

12) 2314 - Intravenous medication administration (IV): Preparation and administration of medication into the vein.

13) 3520 - Pressure ulcers care: Facilitating the healing of pressure ulcers.

14) 3660 - Wound care: Prevention of complications and promotion of wound healing.

15) 2930 - Surgical preparation: Providing care for the patient immediately before surgery and confirmation of required procedures/tests and documentation in the clinical record.

16) 4030 - Hemoderivative administration: Administration of blood or hemoderivatives and monitoring of the patient's reaction.

17) 4200 - Intravenous therapy: Administration and monitoring of fluids and intravenous medicines.

18) 4238 - Vessel puncture: venous blood sample - Collection of venous blood sample from a non-cannulated vein.

19) 5602 - Teaching: disease process - Care for the patient so they can understand information regarding a specific process of the disease.

20) 5618 - Teaching: procedure/treatment - Preparation of the patient to understand and be mentally prepare for prescribed procedure or treatment.

21) 6650 - Supervision: Continuous and purposeful acquisition, interpretation and synthesis of patient data for decision making.

22) 6480 - Control of the environment: Management of the environment of the patient for therapeutic benefit, sensory appeal and psychological well-being.

23) 7830 - Employee Supervision: Facilitation of offering highly skilled care for the patient by others.

24) 7722 - Preceptor: employee - Assistance and support to a new or transferred employee through a planned orientation to an specific clinic area.

25) 7840 - Supplies Control: Acquisition and management warranty of items suitable for providing patient care.

26) 7620 - Checking of controlled substances - Promotion of proper use and management of the security of controlled substances.

27) 7650 - Delegation: Transfer of responsibility for the conduct of patient care, while maintaining accountability for results.

28) 7710 - Support for the doctor: Collaboration with doctors to provide quality care for the patient.

29) 7726 - Preceptor: Student - Assistance and support for learning expectations for a student.

30) 7820 - Control of samples for exams - Obtaining, preparation and storage of samples for laboratory examination.

31) 7850 - Employee development: Development, management and monitoring of team competence.

32) 8100 - Referrals: Organization of services by other professional or institution.

33) 8060 - Transcript of prescriptions: Transfer of information from prescription sheets to nursing care planning and documentation system.

34) 8140 - Shift management: Exchange of essential information about patient care with another nursing team at switch of shift.

35) 3540 - Pressure ulcer prevention - Pressure ulcer prevention for an individual at high risk of developing ulcers.

36) Locate patient companion*

37) Find professional cleaning*

38) Register patient removal in specific worksheet*

39) Separate and prepare medical records for hospitalization*

40) Find doctor*

41) Call for electrocardiogram (ask to refer patient)*

42) Prepare monthly range of employees*

43) Manage interpersonal relations; Manage the unit*

44) Provide comprehensive and holistic care*

45) Request the management of the institution's structures*

46) Perform daily ranges of work*

47) Manage the implementation of the prescribed diagnostic laboratory tests*

48) Prepare and circulate the material on suture procedure room*

* Non-registered activity at Nursing Interventions Classification

In relation to assignments shared with physical therapist, only one has been identified: Oxygen therapy-Administration of oxygen and monitoring of its effectiveness (NIC-3320). Two assignments were recognized as shared with physiotherapist and doctor: Documentation
- Relevant data record in clinical record (NIC-7920) and Exchange of information on health care: Provision of essential information on patient care to another health professional (NIC-7960). Twelve assignments resulted as shared with doctors (Chart 2). 
Chart 2 - Assignments of nurses shared with doctors in the Emergency Service, São Paulo, Brazil, 2017

\begin{tabular}{|l|}
\hline Assignments shared with doctors \\
\hline 1) 0580 - Urinary catheterization: Insertion of a catheter in the bladder for temporary or permanent drainage of urine. \\
\hline 2) 1400 - Pain control: Pain relief or pain reduction up to a level of comfort that is acceptable to the patient. \\
\hline 3) 3120 - Insertion and stabilization of artificial airways: Insertion or insertion assistance and stabilization of an artificial airway. \\
\hline 4) 6362 - Triage: Catastrophe: Rank of patient care priorities for urgent treatment while scarce resources are allocated. \\
\hline 5) 6200 - Emergency care - Assessment and actions implementation to save life in urgent situations. \\
\hline 6) 6580 - Physical restraint - Application, monitoring and removal of mechanic or manual restraint used to limit the physical mobility of the patient. \\
\hline 7) 6430 - Chemical restraint - Administration, monitoring and discontinuation of psychotropic agents used to control extreme behavior of an individual. \\
\hline 8) 6680 - Vital signs monitoring: Collection and analysis of cardiovascular, respiratory and body temperature data to determine and prevent complications. \\
\hline 9) 7370 - Discharge plan: Arrangement for the transfer of a patient from one level of care to another, within the same health institution or to another location. \\
\hline 10) 2120 - Hyperglycemia control - Prevention and treatment of blood glucose levels above normal. \\
\hline 11) 2130 - Hypoglycemia control - Prevention and treatment of low blood glucose levels. \\
\hline 12) NCA - Conducting neurological evaluation. \\
\hline
\end{tabular}

Note: NCA - Non-cataloged activity at Nursing Interventions Classification.

\section{DISCUSSION}

Contemporary trend of IPP and expansion of the scope of health professions practice have increased tensions on the borders and the boundaries between professions. In this context, the study sought to identify the role of nurses in the ES in view of IPP and the assumption that the clarity of the assignments of the different professions can contribute to reduce conflicts, fragmentation of care actions, as well as possible omissions, repetitions and/or waste of resources resulting from the isolated work of the professionals $s^{(8,10)}$.

Decree number $94.406 / 87$, which deals with the exercise of Nursing, is broad and does not contemplate the performance of nurses in the $\mathrm{ES}^{(21)}$. In a study carried out in Brazil, the legal competences in the ES were described and fourteen assignments were cited, five of which should only be performed under imminent risk of death and impossibility to be perform by a doctor ${ }^{(22)}$. In consultation to Nursing Council of São Paulo, about the assignments of nurses in the ES, it was recommended research in the Nursing Service Regulation, that is, it is delegated to the institutions the classification of posts and professional categories, with their respective assignments. With the understand that the professionals of hospital institutions are a source of high cost, it is necessary to reflect on the relevance of delegating the institutions to describe the assignments of the professionals, because this can lead to a very heterogeneous set of assignments, in order to decrease spending and possibly increase the risks for patients. A study that assessed the scope of nurses, through the use of protocols, in an ES in the USA, has shown that there are inconsistencies between States in the scope of practice of nurses that are intentionally vague and can harm the practice, changes in training, public policy and the development of research ${ }^{(23)}$.

It was identified that the scope of practice of the nurse in emergency is broad and includes, in care area, from the care of patients with low clinical complexity - through the Reception with Risk Classification - to attending patients at risk of life and psychiatric patients, as well as development of the ES management actions. It was shown 105 assignments, being 48 specific to nurses, one shared with physiotherapist, 12 shared with doctors, two shared with doctor and physiotherapist. It means that $14.2 \%$ of the assignments of nurses in the ES are shared with physiotherapists and/or doctors, but $40 \%(n=42)$ of the cases there was no consensus about the sharing of these assignments. It shows, on the one hand, the expansion of scope of the practice of professions and the constitution of common assignments to the three professionals; on the other hand, the presence of potential conflicts due to the lack of definition of these assignments and the respective responsibilities in the ES.

Regarding the assignments considered specific to nurses, were included the activities of hygiene, therapeutic procedures (medications), venous catheters insertions, supplies of materials for patient care and nursing staff training. A national study described as necessary for the practice of nurses in the ES the development of assistance skills defined as: The ability of nurses to individually assist fulfilling the needs and expectations of patients and ensuring a care based on their own scientific knowledge and technical procedures essential to produce result with quality ${ }^{(24)}$.

The assignment identified as shared with physiotherapists was the oxygen therapy, which composes respiratory care, a prominent area in the practice of these professionals in the ES. National studies cite the oxygen therapy as a responsibility both of the physical therapist ${ }^{(25)}$ and the nurses ${ }^{(26)}$ from the ES, which proves to be their duties and a need of common action between them ${ }^{(27)}$. However, it has not been reported sharing in activities such as pain control, whereas the review study describes the reduction of pain complaint associated with musculoskeletal disorders as one of the pillars of physical therapy indication in the $\mathrm{ES}^{(28)}$. This may reflect the expansion of the scope of practice of nurses and physiotherapists in the $\mathrm{ES}$, and has not yet reached consensus on some assignments.

It was included in activities shared with doctors the physical and chemical restraint, for patients with moderate and severe mental disorder. A national study, conducted with these patients in the ES, describes as essential the nursing care, as well as your role in the management of the interprofessional team assistance ${ }^{(29)}$. 
Historically, nurses share with doctors the care for critical patients at risk of living in the ES. It was identified the advanced life support actions - which the literature points out to the need of the interdisciplinary team practice ${ }^{(30)}-$, and the insertion and stabilization of artificial airways, demonstrating the common practice between doctors and nurses to achieve the best patient care. Studies that include doctors and nurses showed that intense teamwork is associated to high perception of job satisfaction ${ }^{(31)}$.

The urinary catheterism can only be carried out by nurses in nursing team ${ }^{(32)}$. It was identified as a shared assignment with doctors. Researches demonstrate that the prevention of urinary infection associated with the catheter should be the front line of care quality, in which the engagement of doctors and nurses is fundamental. This shows that the collaborative action among these professionals improve patient safety ${ }^{(33)}$.

Patient monitoring, for example, the blood glucose and vital signs control and the neurological assessment was identified as one of shared duties between nurses and doctors. A study carried out in Australia shows the importance of this collaborative work between the professions, since patients received in the ES have a risk of rapid clinical deterioration, that can be identified before a serious adverse event, through physiological changes ${ }^{(34)}$.

Despite the absence of consensus on the share of $40 \%(n=42)$ of assignments, the study was interrupted considering that three rounds of the Delphi Technique ${ }^{(18)}$ are usually sufficient for reaching consensus at the moment and in the context of research, and understanding that the scope of the role of the nurse is influenced by the characteristics and institutional culture in which they are inserted.

\section{Study limitations}

The lack of literature about IPP in the ES made it harder to compare results to related studies, especially on the national scenario, and designed this study. The generalization of this find can be limited, since it depends on the legislation and rules of the hospital institutions in which these professionals work. We emphasize that the ABEn-CEPEn database is a valuable source of information for nursing research.

\section{Contributions to Nursing}

Clarity of professionals' assignments is one of the pillars for the cohesive development of IPP due to the alignment of scopes of professions that work in the ES. And so, decreases conflicts, improves the quality and safety of care, making it more effective and with proper cost due to an assistance plan integrated and patient-centered.

\section{CONCLUSION}

The initial mapping of the specific actions of the nurses was carried out, that resulted in 48 assignments; of which 35 were categorized by the Nursing Interventions Classification and 13 had no correspondence in the taxonomy. Followed by the mapping of assignments of nurses, physiotherapist, and/or doctors. It resulted in 15 assignments, of which 12 were shared with doctors, one shared with physiotherapist and two with doctors and physiotherapist.

However, 42 assignments reached no consensus on sharing and present potential conflicts due to the lack of definition of duties that are specific and/or common between different professionals in the ES. This result also highlights the need to broaden the debate about IPP in the ES from the identification of the needs of the patients.

The ES is a dynamic environment and the development of IPP improves the patient and professionals experience, the care outcomes and, in addition, avoids wasted resources. This study demonstrates the ongoing movement of professional borders flexibility, which can improve the access to and quality of health care, since more patients can be assisted with cooperation between different professionals in the team. However, so this change of practices be consolidated, it is necessary to change the training of health professionals, emphasizing the interprofessional education and the professional regulation, in order to include the collaborative interpersonal work focused on needs and care of patients.

\section{REFERENCES}

1. Courtenay M, Nancarrow S, Dawson D. Interprofessional teamwork in the trauma setting: a scoping review. Hum Resour Health [Internet]. 2013 [cited 2017 Apr 27];11(1):57. Available from: https://doi.org/10.1186/1478-4491-11-57

2. Sprivulis PC, Da Silva J, Jacobs IG, Frazer AR, Jelinek GA. The association between hospital overcrowding and mortality among patients admitted via Western Australian emergency departments. Med J Aust [Internet]. 2006 [cited 2016 Apr 27];184(5):208-12. Available from: https://www.mja.com.au/system/files/issues/184_05_060306/spr10395_fm.pdf

3. Bodenheimer T, Sinsky C. From Triple to Quadruple Aim: Care of the Patient Requires Care of the Provider. Ann Fam Med [Internet]. 2014 [cited 2016 Jun 25];12(6):573-6. Available from: http://www.annfammed.org/content/12/6/573.full.pdf

4. Chang WY, Ma JC, Chiu HT, Lin KC, lee PH. Job satisfaction and perceptions of quality of patient care, collaboration and teamwork in acute care hospitals. J Adv Nurs. 2009;65(9):1946-155.

5. Hardin L, Kilian A, Spykerman K. Competing health care systems and complex patients: An inter-professional collaboration to improve outcomes and reduce health care costs. J Interprof Educ Pract [Internet]. 2017 [cited 2017 Aug 14]; 7:5-7. Available from: https://doi. org/10.1016/j.xjep.2017.01.002

6. Reeves S, Fletcher S, Barr H, et al. BEME Systematic review of the effects of interprofessional education: BEME Guide no. 39 Med Teach. Jul 2016; 38 (7): 656-68 
7. Gaboury I, Bujold M, Boon H, Moher D. Interprofessional collaboration within Canadian integrative healthcare clinics: Key components. Soc Sci Med. 2009;69(5):707-15.

8. Reeves S, Perrier L, Goldman J, Freeth D, Zwarenstein M. Interprofessional education: effects on professional practice and healthcare outcomes (update). Cochrane Database Syst Rev. 2013;(3):CD002213. doi: 10.1002/14651858.CD002213.pub3.

9. D'amour D, Oandasan I. Interprofessionality as the field of interprofessional practice and interprofessional education: an emerging concept. J Interprof Care. 2005;19(sup 1):8-20.

10. Nancarrow SA, Booth A, Ariss S, Smith T, Enderby P, Roots A. Ten principles of good interdisciplinary team work. Hum Resour Health [Internet]. 2013 [cited 2017 Sept 30];11(1):19. Available from: https://humanresourcesorganization.biomedcentral.com/ articles/10.1186/1478-4491-11-19

11. Gilbert JH, Orchard C, Bainbridge L. A National interprofessional competency framework [Internet]. Canadá: Canadian Interprofessional Health Collaborative; 2010 [cited 2017 Oct 2] 32p. Available from: https://www.cihc.ca/files/CIHC_IPCompetencies_Feb1210.pdf

12. Hudson CC, Gauvin S, Tabanfar R, Poffenroth AM, Lee JS, O'Riordan AL. Promotion of role clarification in the Health Care Team Challenge. J Interprof Care. 2017;31(3):401-403. doi: 10.1080/13561820.2016.1258393

13. Brault I, Kilpatrick K, D'Amour D, Contandriopoulos D, Chouinard V, Dubois CA, Perroux M, Beaulieu MD. Role clarification processes for better integration of nurse practitioners into primary healthcare teams: a multiple-case study. Nurs Res Pract. 2014;2014:170514. doi: $10.1155 / 2014 / 170514$.

14. Mitchell R, Parker V, Giles M, White N. Review: Toward realizing the potential of diversity in composition of interprofessional health care teams: an examination of the cognitive and psychosocial dynamics of interprofessional collaboration. Med Care Res Rev. 2010;67(1):3-26. doi: $10.1177 / 1077558709338478$.

15. Brown J, Lewis L, Ellis K. Conflict on Interprofessional primary health care teams - can it be resolved? J Interprof Care [Internet] 2011 [cited 2017 Oct 2]; 25: 4-10 Available from: https://www.armstrong.edu/images/uploads/iphc/557038871.pdf

16. Mclnnes S, Peter K, Bonney A, Halcomb E. An integrative review of facilitators and barriers influencing collaboration and teamwork between general practitioners and nurses working in general practice. J Adv Nurs. 2015;71(9):1973-85.

17. Biblioteca Virtual em Saúde: Enfermagem [Internet]. Belo Horizonte (MG): UFMG, c2018 [cited 2018 Sep 23] Teses e Dissertações da ABEn-CEPEn. Available from: http://enfermagem.bvs.br/vhl/colecao-de-fontes-de-informacao/teses-e-dissertacoes-em-enfermagem/ teses-e-dissertacoes-da-aben-cepen/

18. Gracht HA. Consensus measurement in Delphi studies Review and implications for future quality assurance. Technol Forecast Soc Change [Internet] 2012 [cited 2018 Sep 23];79(8):1525-36. Available from: https://doi.org/10.1016/j.techfore.2012.04.013

19. Bulechek GM, Butcher HK, Docheterman JM, Wagnet CM. NIC Classificação das Intervenções de Enfermagem. 6th ed. Rio de Janeiro: Elsevier, 2016. $640 \mathrm{p}$.

20. Vinuto J. A amostragem em bola de neve na pesquisa qualitativa: um debate em aberto. Temáticas. 2014;22(44):203-20.

21. Presidência da República (BR), Casa Civil, Subchefia para Assuntos Jurídicos. Decreto n. 94.406 de 8 de junho de 1987. Dispõe sobre o exercício da Enfermagem, e dá outras providências [Internet]. Diário Oficial da União: República Federativa do Brasil; 1987 [cited 2018 Sep 23]. Jun 19. Seção 1: p. 8853-5. Available from: http://www.planalto.gov.br/ccivil_03/decreto/1980-1989/D94406.htm

22. Morais Filho IA, Martini JG, Vargas MAO, Reibnits KS, Bitencourt JVO, Lazzari D. Competência legal do enfermeiro na urgência/emergência. Enferm Foco. 2016;7(1):18-23.

23. Castner J, Grinslade S, Guay J, Hettinger AZ, Seo JY, Boris L. Registered nurse scope of practice and ED complaint-specific protocols. J Emerg Nurs. 2013;39(5):467-473.e3. doi: 10.1016/j.jen.2013.02.009.

24. Holanda FL, Marra CC, Cunha ICKO. Professional competency profile of nurses working in emergency services. Acta Paul Enferm [Internet]. 2015[cited 2017 Oct 2]; 28 (4): 308-14. Available from: http://dx.doi.org/10.1590/1982-0194201500053

25. Gonçalves ACS. [Clinical profile of patients treated by physical therapy service in urgency and emergency care unit of a public hospital of Minas Gerais]. ASSOBRAFIR Ciênc [Internet]. 2014 [cited 2017 Oct 2]; 5(3): 55-62. Available from: http://www.uel.br/revistas/uel/index.php/ rebrafis/article/view/18166/15576. Portuguese.

26. Beserra PJF, Bittencourt GKGD, Nobrega MML, Garcia TR. [Nursing actions identified in the components of a nursing teams language, at a medical office in a hospital-school]. Rev RENE [Internet]. 2004 [cited 2017 Oct 2];5(2):41-48. Available from: http://www.periodicos.ufc.br/ rene/article/view/5610/4041. Portuguese.

27. Arakaki VSNM, Oliveira AM, Bogossian T, Almeida VS, Silva GD, Ferreira HC. Importance of physiotherapy/nursing multidisciplinary integration about update newborn position in the neonatal intensive care unit. Fisioter Mov [Internet]. 2015 [cited 2017 Oct 2]; 28(3): 43745. Available from: http://dx.doi.org/10.1590/0103-5150.028.003.AO02

28. Cordeiro AL, Lima TG. [Physical Therapy in emergency departments: a systematic review]. Rev Pesq Fisioter . 2017;7(2):276-81. DOI: 10.17267/2238-2704rpf.v7i2.1360. Portuguese.

29. Buriola AA, Kantorski LP, Sales CA, Matsuda LM. Nursing practice at a psychiatric emergency service: evaluation using fourth generation assessment. Texto Contexto Enferm [Internet]. 2016 [cited 2017 Oct 2]; 25(1): e4540014. Available from: http://dx.doi. org/10.1590/0104-070720160004540014 
30. Santana LS; Lopes WS; Queiroz V. [The multidisciplinary team in person at stop watching cardiorespiratory: a review of literature]. Ciênc Praxis [Internet]. 2014 [cited 2017 Oct 2]; 7(13): 49-54. Available from: http://revista.uemg.br/index.php/praxys/article/viewFile/2139/1131. Portuguese.

31. Ajeigbe DO, McNeese-Smith D, Leach LS, Phillips LR. Nurse-physician teamwork in the emergency department: impact on perceptions of job environment, autonomy, and control over practice. J Nurs Adm. 2013;43(3):142-8. doi: 10.1097/NNA.0b013e318283dc23.

32. Conselho Federal de Enfermagem (COFEN). Resolução COFEN-0450/2013. Normatiza o procedimento de Sondagem Vesical no âmbito do Sistema Cofen / Conselhos Regionais de Enfermagem [Internet]. Brasília: COFEN; 2013 [cited 11 de Oct de 2017]. Available from: http:// www.cofen.gov.br/resolucao-cofen-no-04502013-4_23266.html

33. Fakih MG, Heavens M, Grotemeyer J, Szpunar SM, Groves C, Hendrich A. Avoiding Potential Harm by Improving Appropriateness of Urinary Catheter Use in 18 Emergency Departments. Ann Emerg Med 2014; 63(6):761-8.e1. doi: 10.1016/j.annemergmed.2014.02.013.

34. Hosking J, Considine J, Sands N. Recognising clinical deterioration in emergency department patients. Australas Emerg Nurs J. 2014;17(2):59-67. doi: 10.1016/j.aenj.2014.03.001 